\title{
ANÁLISE DISCURSIVA SOBRE A PROTEÇÃO À JUVENTUDE EM RISCO
}

(Discursive analysis about protection to youth at risk)

Kelly Cristina de Almeida Moreira*

(Universidade de Brasília - UnB)

\begin{abstract}
This study seeks to investigate through transitivity processes analysis (Halliday and Matthiessen, 2004), intertextuality (Fairclough, 2003) and the voices present in a media text, the extent to which certain linguistic-discursive representations contribute politically to reduce social inequality of children and adolescents and to reflect how the discursive practices within the education policy can contribute to their integration in the Brazilian school system.
\end{abstract}

Keywords: Critical Discourse Analysis, transitivity processes, intertextuality, children and adolescents at risk

\section{RESUMO}

Busca-se investigar, através das análises dos processos de transitividade (Halliday e Matthiessen, 2004), da intertextualidade (Fairclough, 2003) e das vozes presentes em um texto midiático, em que medida determinadas representações linguístico-discursivas contribuem politicamente para diminuir a desigualdade social de crianças e adolescentes e refletir de que modo as práticas discursivas no âmbito da política educacional podem contribuir para a inserção dos jovens no sistema escolar brasileiro. ${ }^{1}$

1 Mestra e doutoranda em Linguística pela Universidade de Brasília. Atualmente, é professora da Secretaria de Estado de Educação do Distrito Federal. É membro do Grupo Brasileiro de Estudos de Discurso, Pobreza e Identidades, que integra a Rede Latino-Americana de Estudos do Discurso - REDLAD, do Grupo de Estudos de Linguagem do Centro-Oeste (GELCO), da Associação Latino-Americana de Estudos do Discurso (ALED) e da Associação de Linguística Sistêmico-Funcional da América Latina (ALSFAL).

* Este artigo constitui um recorte de minha pesquisa de doutorado, desenvolvida junto ao Programa de Pós-Graduação em Linguística da UnB, dentro do Grupo Brasileiro de Estudos de Discurso, Pobreza e Identidades, que integra a Rede Latino-Americana 
Palavras-chave: Análise de Discurso Crítica, processos de transitividade, intertextualidade, crianças e adolescentes em situação de risco

\section{Introdução}

Este artigo tem como objetivo apresentar uma análise crítica de representações linguístico-discursivas midiáticas, voltadas para a situação de crianças e adolescentes em situação de risco/de exclusão social. A finalidade é apontar práticas discursivas transformadoras, possíveis de beneficiar essa parcela da sociedade tão castigada por situações de opressão, injustiças e iniquidades sociais. Para tanto, buscase examinar elementos léxico-gramaticais presentes no texto de uma reportagem publicada no jornal Correio Braziliense, no dia 20/09/2009, intitulada "Todos envolvidos na proteção", que faz parte de uma série de reportagens sobre "Juventude em risco" apresentadas pelo referido periódico, cuja produção, circulação e consumo na capital federal permite-nos considerá-lo com um jornal de referência, pelo menos no âmbito da capital federal.

O gênero textual selecionado para o estudo (reportagem) permitenos discutir a intertextualidade presente no discurso da mídia impressa (Correio Braziliense), assim como realizar uma análise dos processos de transitividade, com vistas a apontar como essas representações linguístico-discursivas, presentes neste texto midiático, contribuem como forma de política pública para diminuir a desigualdade social entre crianças e adolescentes, bem como para inseri-los dentro do sistema educacional brasileiro.

O estudo encontra-se organizado em cinco partes. No início, discuto questões teóricas e metodológicas concernentes à Análise de

de Estudos do Discurso - REDLAD, formada por cinco países: Argentina, Brasil, Chile, Colômbia e Venezuela. 
Discurso Crítica (ADC), em seguida, apresento alguns pressupostos da Linguística Sistêmico-Funcional (LSF) e os processos de transitividade propostos por Halliday (1994) e Halliday e Matthiessen (2004). Na seção 3, traço um paralelo entre a LSF e a ADC. Na seção 4, enfoco a intertextualidade enquanto categoria de análise. $\mathrm{Na}$ seção 5, faço algumas considerações analíticas sobre o texto selecionado, publicado na mídia. $\mathrm{Na}$ última parte, teço algumas reflexões sobre os resultados alcançados.

\section{A proposta teórico-metodológica da ADC}

Segundo Ramalho (2008:136), “a proposta teórico-metodológica da ADC oferece ferramentas analíticas para o pesquisador mapear conexões entre aspectos sociais semióticos e não semióticos, tendo em vista dois objetivos principais". Esses objetivos, de acordo com a autora, referem-se à investigação de "mecanismos causais discursivos e seus efeitos potencialmente ideológicos” e à reflexão "sobre possíveis maneiras de superar relações assimétricas de poder parcialmente sustentadas por sentidos de textos".

Chouliaraki e Fairclough (1999) sugerem um arcabouço teóricometodológico que dá uma visão geral do que se fazer em ADC. Segundo os autores, devido a sua complexidade, esse arcabouço poderá ser simplificado, dependendo dos objetivos do analista. Os passos sugeridos por Chouliaraki e Fairclough (p.60) são os seguintes:

1) Um problema (atividade reflexiva)

2) Obstáculos para serem superados

(a) análise da conjuntura

(b) análise da prática particular

(i) práticas relevantes

(ii) relações do discurso com outros momentos da prática - discurso como parte da atividade - discurso e reflexividade 
(c) análise do discurso

(i) análise estrutural: a ordem do discurso

(ii) análise interacional

- análise interdiscursiva

- análise linguística e semiótica

3) Função do problema na prática

4) Possíveis maneiras de superar os obstáculos

5) Reflexão sobre a análise

Para Fairclough (2003), a contribuição da pesquisa social crítica está em procurar compreender melhor como são produzidos, pelas sociedades, tantos efeitos benéficos como maléficos, e como os efeitos maléficos podem ser mitigados, ou até mesmo eliminados. Segundo o autor, a pesquisa social crítica começa com questionamentos a respeito de como as sociedades podem prover algumas pessoas com tantos recursos e possibilidades para enriquecer e satisfazer vidas, e como, por outro lado, elas negam a outras esses recursos e possibilidades. Outro questionamento, dentro da proposta teórica faircloughiana, concerne ao problema de como as sociedades em geral podem produzir pobreza, privação, miséria e insegurança na vida das pessoas. Uma das preocupações do autor volta-se para as possibilidades existentes para operar mudanças sociais que reduzam esses problemas e acentuem a qualidade de vida dos seres humanos (Moreira, 2007).

A Análise de Discurso Crítica, como proposta teórico-metodológica, insere-se num campo de estudo em que pesquisadores buscam investigar o envolvimento da linguagem na vida social, cujo sistema aberto é formado por práticas. Assim, objetiva reunir com sucesso a Ciência Social Crítica e a Linguística - mais especificamente a Linguística Sistêmico-Funcional (LSF) - demandando uma contribuição fundamental que se revela na tentativa de estabelecer um modelo analítico que deslinde as relações de poder. É sobre os pressupostos da LSF que tratarei a seguir. 


\section{A Linguística Sistêmico-Funcional e os processos de tran- sitividade}

De acordo com Halliday, o contexto precede o texto. Sua teoria linguística está voltada para o foco social, isto é, ela procura mostrar como as funções sociais determinam a linguagem e como ela se desenvolveu.

O papel do contexto, bem como os significados que o usuário queira atribuir à sentença que produz, são alguns dos pontos de partida da gramática sistêmico-funcional, que se propõe a investigar a variedade de escolhas em termos dos significados que queremos expressar, assim como em termos das palavras que usamos para expressar esses significados (Thompson, 1996: 6). ${ }^{2}$

O texto é a unidade de análise da lingüística sistêmico-funcional e, o contexto onde é produzido, bem como as condições para a sua produção e a maneira como os participantes o organizam para se comunicarem é a rede de significados que permeia a lingüística sistêmico-funcional.

De acordo com Orlando Vian Jr. (2001:151), a proposta teórica hallidyana classifica as maneiras de utilização da língua em três categorias, tendo em vista que (1) usamos a língua para falar de nossa experiência de mundo, inclusive para expressarmos percepções; (2) a língua é também usada para interagirmos com outras pessoas; (3) além de, ao usarmos a língua, organizarmos o que dizemos, logo, cada uma dessas categorias é usada como base para explorarmos como os significados são criados e compreendidos.

Essas categorias podem ser referidas como metafunções que, de acordo com a perspectiva multifuncional adotada pela lingüística sistêmico-funcional, são colocadas em prática simultaneamente toda vez que nos comunicamos.

Essas funções desempenhadas simultaneamente são: a função ideacional na representação de experiências e do mundo; a função

2 In: VIAN Jr., Orlando (2001). Sobre o conceito de gêneros do discurso: diálogos entre Bakhtin e a linguística sistêmico funcional. (p.150) 
interpessoal que se constitui na interação social entre os participantes no discurso; e a função textual que une partes de um texto num todo de maneira coerente, constituindo e ligando esse texto a contextos situacionais.

Podemos verificar que essas funções são expressas através das três variáveis de registro:

a) a variável campo, que é expressa através da função ideacional;

b) a variável relações, que é expressa pela função interpessoal;

c) a variável modo, que é expressa pela função textual.

De acordo com Eggins (1994: 9), a teoria de registro tem como função descrever o impacto das dimensões do contexto imediato da situação de um evento no modo como a linguagem é usada.

Segundo Vian Jr., as variáveis servem para interpretar o contexto social de um texto e a maneira pela qual os significados são tocados. Para ele, o texto será materializado por meio da gramática, mas é perpassado por características da situação e da cultura nas quais é produzido.

Considerando que este trabalho tem como foco a análise dos processos de transitividade no discurso midiático, faço a seguir uma breve consideração a respeito dos tipos de processos.

Conforme propõe Halliday (1994: 107), os três principais tipos de processos do sistema de transitividade são os MATERIAIS, os MENTAIS e os RELACIONAIS. No entanto, existem ainda três tipos de processos intermediários: os COMPORTAMENTAIS, os VERBAIS e os EXISTENCIAIS.

Os processos MATERIAIS concernem à experiência do mundo externo, isto é, do mundo que nos cerca. Segundo Halliday, a forma prototípica da experiência 'externa' é a das ações e eventos: as coisas acontecem, e as pessoas, ou outros agentes, fazem coisas, ou as fazem acontecer. Por isso, esses são os processos do "fazer" e envolvem participantes como "atores".

Os processos MENTAIS estão ligados à experiência interna, àquilo que experienciamos como acontecendo dentro de nós mesmos, no mundo da consciência e da imaginação. São os processos do "sentir" e por isso envolvem participantes humanos. 
Os RELACIONAIS são os processos de classificação e identificação. De acordo com Halliday, nas orações relacionais, há duas partes para o 'ser': algo é dito como 'sendo' outra coisa. Em outras palavras, uma relação está sendo estabelecida entre duas entidades separadas. Ainda, segundo o autor, toda língua acomoda, em sua gramática, alguma construção sistemática de processos relacionais. Há três tipos principais de processos relacionais: (1) intensivo: 'x é a'; (2) circunstancial: 'x está em a' (onde 'está em ' significa 'está em, sobre, para, com, acerca, ao longo, etc.'); (3) possessivo : 'x tem a'. Cada um desses se divide em dois modos distintos:
(a) atributivo
'a é um atributo de $\mathrm{x}$ '
(b) identificador
'a é a identidade de x'

Podemos observar, portanto, seis categorias de processos relacionais, como exemplificado a seguir:

1 - atributivos intensivos

Ex.: "Minha vida é assim."

2 - atributivos circunstanciais

Ex.: A professora estava na sala de aula.

3 - atributivos possessivos

Ex.: Eu tenho uma casa.

4 - identificativos intensivos

Ex.: João é o mais velho dos amigos.

5 - identificativos circunstanciais

Ex.: Sábado foi o dia do casamento.

6 - identificativos possessivos

Ex.: A casa era da mãe dela. 
Os processos COMPORTAMENTAIS estão no limite entre os materiais e os mentais. São aqueles que representam manifestações exteriores de atividades internas, ou seja, a externalização de processos da consciência e dos estados fisiológicos.

No limite entre mental e relacional, está a categoria dos processos VERBAIS: relações simbólicas construídas na consciência humana e efetivadas na forma de língua como: dizer e significar. Os participantes são, geralmente, humanos.

No limite entre relacional e material, estão os processos que se referem à existência, os EXISTENCIAIS, pelos quais fenômenos de todos os tipos são reconhecidos como 'ser' - existir, ou acontecer.

A escolha pelos tipos de processos revela a forma como o texto midiático mostra as ações que devem ser desenvolvidas pelo Estado, bem como esse texto atribui características aos adolescentes que devem receber as ações do Estado, ou seja, aqueles "que se encontram em situação de risco”.

\section{A Linguística Sistêmico-Funcional e a Análise de Discur- so Crítica}

“A linguagem é como é por causa de sua função na estrutura social, e a organização dos sentidos comportamentais deve propiciar percepção de suas fundações sociais" (HALLIDAY, 1973: 65).

A dimensão que envolve aspectos discursivos, que fazem da língua um contrato social, será enfocada a partir dos estudos de Fairclough (2003) sobre os significados da linguagem, mas com o respaldo da Linguística Sistêmico-Funcional (LSF), no que concerne aos aspectos linguísticos, de acordo com os parâmetros de Halliday (2004), cuja proposta teórico-metodológica será utilizada como ferramenta na análise da dimensão interior da linguagem, a partir do estudo da relação entre os processos de transitividade (Gramática da Experiência) e outros elementos e aspectos da vida social. 
É necessário, contudo, destacar que o instrumento inicial para análise é o discurso, um elemento inserido nos processos sociais, ou melhor, nas práticas. Nessa perspectiva, revela-se extremamente significativo, pois ao estabelecer conexão com os eventos sociais provocam efeitos, acarretam mudanças. Tais efeitos têm duração flexível, podem ser de longo ou curto prazo: pode-se, por exemplo, contribuir para formação de identidade de consumidores ao expor-se demasiadamente a textos publicitários ou, ainda, implodir guerras e contribuir para mudanças na educação.

Em Analysing discourse: textual analysis for social research, Fairclough (2003: 26) sugere que o discurso figura de três principais maneiras na prática social: como gênero, através dos modos de agir; como discursos, através dos modos de representar; e como estilos, através dos modos de ser. Em suas palavras:

Uma das maneiras de agir e interagir é por meio da fala ou da escrita, assim o discurso figura primeiramente 'como parte da ação' (...) Em segundo lugar, o discurso figura nas representações que sempre são partes de práticas sociais - representações do mundo material, de outras práticas sociais, representações próprias reflexivas da prática em questão. (...) Em terceiro lugar e finalmente, discurso figura conjuntamente com expressões corporais ao constituir modos particulares de ser, identidades sociais ou pessoais. (Tradução minha)

Deve-se observar que, além de representação, o discurso constitui uma maneira de significar o mundo.

Fairclough (2003) também vê os textos como multifuncionais, porém, de maneira diferente. Prefere falar sobre três principais tipos de significações: ação, representação e identificação: a representação corresponde à função 'ideacional' de Halliday e trata da experiência, um modo de refletir a 'realidade' na língua. A ação aproxima-se da função 'interpessoal', apesar de sua ênfase maior ser no texto como modo de (inter) agir em eventos sociais, e também possa ser visto como representando relações sociais. A maior parte do que Fairclough inclui 
como identificação está na função 'interpessoal' de Halliday, embora este último não a diferencie separadamente. Fairclough não distingue uma função 'textual' também separadamente, prefere incorporá-la como ação.

Para Fairclough (2003), focalizar a análise de textos, na interação de ação, representação e identificação, traz uma perspectiva social para o âmago do texto, para o seu mais afinado detalhe. Sempre de acordo com Fairclough, há uma correspondência entre ação e gêneros, representação e discursos, identificação e estilos. Gêneros, discursos e estilos são tidos como elementos de ordens de discurso no nível da prática social, uma vez que são meios relativamente estáveis e duráveis de agir, representar e identificar.

\section{A intertextualidade}

De acordo com Fairclough (2001: 114), “a intertextualidade diz respeito à propriedade que têm os textos de serem cheios de fragmentos de outros textos". Isso pode ocorrer explicitamente ou, então, de forma mesclada, podendo um texto assimilar, contradizer, ecoar ironicamente, e assim por diante, outro texto. Segundo o autor, em termos de produção, uma perspectiva intertextual acentua a historicidade dos textos, isto é, a maneira como eles sempre constituem acréscimos às 'cadeias de comunicação verbal' existentes, como postula Bakhtin (1986: 94), consistindo em textos prévios aos quais respondem. Em termos de distribuição, uma perspectiva intertextual é útil na exploração de redes relativamente estáveis em que os textos se movimentam, sofrendo transformações predizíveis ao mudarem de tipo de texto a outro (por exemplo, os discursos políticos frequentemente se transformam em reportagens). Já em termos de consumo, uma perspectiva intertextual é útil ao acentuar que não é apenas 'o texto', nem mesmo apenas os textos que intertextualmente o constituem, que moldam a interpretação, mas também os outros textos que os intérpretes variavelmente trazem ao processo de interpretação (Fairclough, 2001: 114). 
Fairclough ainda se refere à intertextualidade manifesta, ou seja, a "constituição heterogênea de textos por meio de outros textos específicos (no texto, se recorre explicitamente a outros textos específicos)" (2001: 114). Cometam Resende e Ramalho (2006: 65-66):

Uma questão inicial no estudo da intertextualidade em um texto é a verificação de quais vozes são incluídas e quais são excluídas, isto é, que ausências significativas podem ser observadas. Em seguida, analisando-se sua presença, é interessante examinar a relação que se estabelece entre as vozes articuladas. Quando uma voz "externa" é articulada em um texto, tem-se (pelo menos) duas vozes que podem representar duas diferentes perspectivas, com seus respectivos interesses, objetivos, etc. A relação entre essas vozes pode ser harmônica, de cooperação, ou pode haver tensão entre o texto que relata e o texto relatado.

Com o respaldo das observações acima destacadas, pode-se afirmar que a categoria da intertextualidade tornou-se produtiva na análise empírica apresentada a seguir, justamente em virtude de o texto midiático selecionado estar voltado para o discurso legal e procurar inserir o discurso institucional como forma de demonstrar as ações desenvolvidas pelo governo do Distrito Federal.

\section{Considerações analíticas}

Como dito anteriormente, o texto escolhido para esta análise é um fragmento de reportagem publicada no jornal Correio Braziliense, no dia 20/09/2009, intitulada “Todos envolvidos na proteção”, que faz parte de uma série de reportagens sobre "Juventude em risco" apresentadas pelo referido jornal.

Como podemos observar, há uma predominância de processos materiais $(56,4 \%)$. Processos materiais envolvem ações do mundo físico, que têm como participantes atores, meta ou extensão e beneficiários. No caso da reportagem em questão, os atores envolvidos nos processos 
materiais são: educadores, reação do Estado, desafio do governo, Secretaria de Educação, coordenadora da Política de Promoção à Cidadania e Cultura de Paz, secretaria, professores, docentes. Os participantes que fazem papel de meta ou extensão são: alunos em situação de vulnerabilidade, ação conjunta de pais e do Estado, o resgate dos direitos garantidos no Estatuto da Criança e do Adolescente (ECA), as ações de proteção aos meninos e meninas que se encontram em situação de risco. Isso demonstra que as ações que devem ser desenvolvidas na proteção de crianças e adolescentes em situação de risco devem ter como responsáveis seus professores, que serão treinados pela Secretaria de Educação.

Do ponto de vista do significado representacional, o discurso da mídia mostra as ações que devem ser desenvolvidas pelo Estado (predominância dos processos materiais), contudo, podemos observar que quem está sendo preparado para efetivar essas ações são os educadores, que aparecem como primeiro participante dos processos "se preparam" e "resgatar" já no subtítulo da reportagem, como podemos observar abaixo:

(1) Educadores se preparam para resgatar alunos em situação de vulnerabilidade. Problema, porém, exige ação conjunta de pais e do Estado

Os processos relacionais representam 24\% dos processos encontrados no texto. De acordo com Halliday (1994), há uma relação de identificação ou de atribuição de valores aos participantes do processo relacional. Os exemplos abaixo demonstram relações de atribuição:

(2) quando uma criança é vítima de violência (pr. Rel. atributivo intensivo)

\begin{tabular}{|c|c|c|c|}
\hline quando & uma criança & é & vítima de violência \\
\hline circunstância & portador & Pr. relacional & atributo \\
& & $\begin{array}{c}\text { atributivo } \\
\text { intensivo }\end{array}$ & \\
& & & \\
\hline
\end{tabular}


(3) o desafio do governo é justamente fortalecer e articular as ações de proteção aos meninos e meninas que se encontram em situação de risco (pr. Rel. atributivo intensivo)

\begin{tabular}{|c|c|c|l|}
\hline $\begin{array}{c}\text { O desafio } \\
\text { do governo }\end{array}$ & é & justamente & $\begin{array}{l}\text { fortalecer e articular as ações de } \\
\text { proteção aos meninos e meninas } \\
\text { que se encontram em situação de } \\
\text { risco }\end{array}$ \\
\hline portador & $\begin{array}{c}\text { Pr. relacional } \\
\text { atributivo } \\
\text { intensivo }\end{array}$ & circunstância & atributo \\
\hline
\end{tabular}

(4) meninos e meninas que se encontram em situação de risco (pr. Rel. atributivo circunstancial)

\begin{tabular}{|c|c|c|c|c|}
\hline $\begin{array}{c}\text { meninos e } \\
\text { meninas }\end{array}$ & que & se & encontram & em situação de risco \\
\hline portador & portador & & $\begin{array}{c}\text { Pr. relacional } \\
\text { atributivo } \\
\text { circunstancial }\end{array}$ & atributo \\
\hline
\end{tabular}

De acordo com Fairclough (2003: 65), gêneros constituem “o aspecto especificamente discursivo de maneiras de ação e interação no decorrer de eventos sociais”. Para Resende e Ramalho (2008: 62), "quando se analisa um texto em termos de gênero, o objetivo é examinar como o texto figura na (inter)ação social e como contribui para ela em eventos sociais concretos". Segundo as autoras, além da estrutura genérica, uma das categorias analíticas relacionadas "a maneiras de agir discursivamente em práticas sociais” exemplificadas por Fairclough, na análise do significado acional, é a intertextualidade.

$\mathrm{Na}$ análise do significado acional da reportagem, a intertextualidade pode ser observada na presença do Estatuto da Criança e do Adolescente, nas citações de ações do Governo e da Secretaria de Educação, bem como através do discurso da coordenadora da Política de Promoção à 
Cidadania e Cultura de Paz, da secretaria, como podemos observar nos trechos (5), (6) e (7) a seguir:

(5) Ter a sensibilidade para perceber quando uma criança é vítima de violência é tão importante quanto a reação do Estado para the assegurar o resgate dos direitos garantidos no Estatuto da Criança e do Adolescente (ECA).

(6) Desde o começo de 2008, a Secretaria de Educação deu início a um plano estratégico de enfrentamento à violência escolar.

(7) O livro Revelando tramas, descobrindo segredos: violência e convivência nas escolas é resultado dessa iniciativa.

Nos trechos (8) e (9), podemos observar a presença do discurso direto, isto é, "a citação pretensamente fiel do que foi dito, com marcas de citação (aspas ou travessão)” (RESENDE e RAMALHO, 2008: 66). Em ambos os trechos há a presença da voz da coordenadora da Política de Promoção à Cidadania e Cultura de Paz, da Secretaria de Educação.

(8) "Fizemos o mapeamento da violência no âmbito escolar. Conhecemos a realidade e, a partir daí, surgiu o livro, que é utilizado como referência de estudo para os professores", cita Relcy Caridé, coordenadora da Política de Promoção à Cidadania e Cultura de Paz, da secretaria.

(9) "A meta é qualificar o olhar dos educadores, do porteiro, da merendeira, de modo que qualquer um possa identificar sinais de bullying, violência psicológica e física”, explica Relcy.

Como bem observam Resende e Ramalho (2008: 67):

A representação do discurso não é uma mera questão gramatical, ao contrário, é um processo ideológico cuja relevância deve ser considerada. Analisar em textos quais vozes são representadas em discurso direto, quais são representadas em discurso indireto e quais as conseqüências disso para a valorização ou depreciação do que foi dito e daqueles(as) 
que pronunciaram os discursos relatados no texto pode lançar luz sobre questões de poder no uso da linguagem.

O texto da reportagem, que começa com a palavra "Educadores", apenas dá voz ao discurso institucional da Secretaria de Educação. As vozes dos professores e até mesmo dos pais, principais atores no processo de proteção articulado pela referida secretaria, são apagadas no discurso. Os primeiros participantes, os educadores, são apenas citados no texto e os segundos, os pais, aparecem apenas no subtítulo da reportagem, sendo totalmente retirados da matéria publicada. Isso também pode ser observado dentro do significado representacional da linguagem, quando analisamos os participantes e processos dentro da função ideacional. Os educadores estão na posição de atores dos processos materiais (10) e (11) que se encontram na voz passiva, ou seja, são atores de ações desencadeadas pelo governo:

(10) Educadores se preparam para resgatar alunos em situação de vulnerabilidade.

(11) E no dia $1^{o}$ deste mês, um grupo de docentes começou a ser treinado no projeto Escola que Protege, em parceria com a Universidade de Brasília (UnB).

Ou são a meta do processo material (12) que identifica qual é o verdadeiro objetivo do governo :

(12) "A meta é qualificar o olhar dos educadores, do porteiro, da merendeira, de modo que qualquer um possa identificar sinais de bullying, violência psicológica e física”.

Observamos que o título da reportagem é "Todos envolvidos na proteção”, contudo a análise dos processos materiais permite-nos sugerir que o peso maior das ações recai, na realidade, sobre os educadores, sobretudo, porque em nenhum momento é mencionado no texto o envolvimento dos pais ou responsáveis na execução dessa proteção. 
Pode-se considerar que isso se deve ao fato de que, muitas vezes, o risco se encontra dentro do próprio lar dessas crianças e adolescentes.

\section{Considerações finais}

Os processos relacionais atribuem características aos adolescentes que devem receber as ações do Estado, ou seja, aqueles "que se encontram em situação de risco", enquanto a intertextualidade presente no discurso da reportagem apresenta uma identificação concernente ao discurso do Governo, que propõe uma forma de política pública na tentativa de solução do problema da desigualdade social e da inclusão de crianças e adolescentes em situação de rua e/ou de risco dentro do sistema educacional. Contudo, essas ações devem ser desenvolvidas pelos educadores, que estão sendo preparados para isso, mas que não possuem voz dentro desse processo.

É relevante observar, ainda, que este estudo se propôs a analisar os processos de transitividade e a intertextualidade presentes no texto midiático. Outras questões como a multimodalidade e a estrutura do texto jornalístico deverão ser contempladas em pesquisas futuras.

Recebido em: outubro de 2009 Aprovado em: dezembro de 2009 kelly.kcam@gmail.com

\section{Referências Bibliográficas}

CHOULIARAKI, L. \& FAIRCLOUGH, N. Discourse in Late Modernity. Rethinking critical discourse analysis. Edinburgh: Edinburgh University Press, 1999.

EGGINS, Suzanne \& MARTIN, J.R. "Géneros y registros del discurso". In: El discurso como estrutura y processo. Estúdios del discurso, uma introducción multidisciplinaria. Org. Teun A. van Dijk. Barcelona: Editorial Gedisa, 1997. 
EGGINS, Suzanne. "The grammar of experiential meaning: TRANSITIVITY”. In: An Introduction to Systemic Functional Linguistics. New York - London: Continuum, 2004.

FAIRCLOUGH, N. Discurso e mudança social. Coord. trad. téc. pela prof. Izabel Magalhães. Brasília: Editora Universidade de Brasília, 2001. (Discourse and social change).

. Analysing Discourse. Textual analysis for social research. London and New York: Routledge, 2003.

HALLIDAY, M. A. K. “Estructura y Function del Lenguaje”. In: J. Lyons (ed.) Nuevos horizontes en la lingüística. Ed. Cast. Madrid: Alianza, p.145-173, 1975.

. "The Functional Basis of Language", in B. Bernstein (ed.) Class, Codes and Control. London: Routledge \& Kegan Paul, 1973, p. 343-366, 1994. (Traduzido por Rodolfo Ilari)

. An Introduction to Funcional Grammar, 2a. Ed. Londres, Nova York, Sidney, Auckland: Edward Arnold, 1994.

HALLIDAY, M. A. K. \& HASAN. Language, Context and: aspects of language in a social-semiotic perspective. Oxford University Press, 1985. HALLIDAY, M. A. K. \& MATTHIESSEN. An Introduction to Functional Grammar. 3a Ed. Londres: Arnold, 2004.

MOREIRA, Kelly Cristina de Almeida. Discurso de adolescentes em situação de rua: da ruptura familiar à exclusão. Brasília: UnB, 2007. (Dissertação de Mestrado inédita).

RAJAGOPALAN, K. Por uma lingüística crítica: linguagem, identidade e a questão ética. São Paulo: Parábola Editorial, 2003.

RAMALHO, V.C.V.S. Discurso e ideologia na propaganda de medicamentos: um estudo crítico sobre mudanças sociais e discursivas. Brasília: UnB, 2008. (Tese de Doutorado inédita).

RESENDE, Viviane de Melo \& RAMALHO, Viviane. Análise de discurso crítica. São Paulo: Ed. Contexto, 2006.

SILVA, D. E. G. Gramática e contexto na perspectiva funcional do discurso. In: Estudos de Linguagem: Inter-relações e Perspectivas. Org.: et al. Campo Grande, MS: Editora UFMS, p. 55-70, 2003.

SILVA, D. E.G. Identidades enfraquecidas versus cidadania cultural. In: Joachin Sèbastien (Org.). Diversidade cultural, linguagens e identidades. Recife: Elógica, vol. 1, p. 51-68, 2007. 
SILVA, D.E.G. Critical Discourse Analysis and the functional bases of language. In: BARBARA, Leila \& SARDINHA, Tony Berber (Ed.). Proceedings of The 33rd International Systemic Functional Congress (PUCSP, São Paulo, Brazil), p. 932-949, 2007.

SILVA, D. E. e RAMALHO, V. “Análise de Discurso Crítica: representações sociais na Mídia”. In: Glaucia Lara et all, Estudos do Discurso hoje, vol. 2. Rio de Janeiro: Editora Nova Fronteira, 2008.

SILVA, D.E.G. A pobreza no contexto brasileiro: da exclusão econômica e social à ruptura familiar. In: Laura Pardo (org), Revista Discurso y Sociedad,vol. 2 (2), p. 265-296, 2008. www.dissoc.org

THOMPSON, G. Introducing functional grammar. London: Arnold, 1996. THOMPSOM, John B. Ideologia e cultura moderna. Petrópolis: Vozes, 1995.

Vozes, 2002.

- A mídia e a modernidade: uma teoria social da mídia. Petrópolis:

VAN DIJK, T. A. La noticia como discurso. Comprensión, estructura y Producción de la información. Barcelona: Paidós Comnicación, 1990.

Discurso e Poder. Org. Judith Hoffnagel e Karina Falcone. São Paulo: Contexto, 2008.

VIAN JR., Orlando. "Sobre o conceito de gêneros do discurso: diálogos entre Bakhtin e a lingüistica sistêmico funcional”, in Beth Brait: (Org.) Campinas, SP: Pontes: São Paulo: Fapesp, 2001.

\section{Anexo}

(Correio Braziliense - Cidades. Brasília, 20 de setembro de 2009.) TODOS ENVOLVIDOS NA PROTEÇÃO

Educadores se preparam para resgatar alunos em situação de vulnerabilidade. Problema, porém, exige ação conjunta de pais e do Estado

ADRIANA BERNARDES 
Ter a sensibilidade para perceber quando uma criança é vítima de violência é tão importante quanto a reação do Estado para lhe assegurar o resgate dos direitos garantidos no Estatuto da Criança e do Adolescente (ECA). O desafio do governo é justamente fortalecer e articular as ações de proteção aos meninos e meninas que se encontram em situação de risco. No Distrito Federal, já existem políticas nessa direção, mas, como o Correio mostrou, a resposta ainda demora mais do que a gravidade dos casos detectados na rede pública de ensino exige.

Desde o começo de 2008, a Secretaria de Educação deu início a um plano estratégico de enfrentamento à violência escolar. O livro Revelando tramas, descobrindo segredos: violência e convivência nas escolas é resultado dessa iniciativa. "Fizemos o mapeamento da violência no âmbito escolar. Conhecemos a realidade e, a partir daí, surgiu o livro, que é utilizado como referência de estudo para os professores”, cita Relcy Caridé, coordenadora da Política de Promoção à Cidadania e Cultura de Paz, da secretaria.

Além disso, a secretaria elaborou um manual com orientações sobre como diretores e professores devem agir em situações de violência no âmbito escolar. Em junho deste ano, cerca de 600 profissionais da rede passaram por capacitação. E no dia $1^{\circ}$ deste mês, um grupo de docentes começou a ser treinado no projeto Escola que Protege, em parceria com a Universidade de Brasília (UnB). "A meta é qualificar o olhar dos educadores, do porteiro, da merendeira, de modo que qualquer um possa identificar sinais de bullying, violência psicológica e física”, explica Relcy. 